Running head: DISCOURSES AND TEENAGE PREGNANCY

\title{
Public Discourses about Teenage Pregnancy: Disruption, Restoration, and Ideology
}

\author{
Jennifer J. Bute \\ Department of Communication Studies \\ Indiana University-Purdue University Indianapolis \\ Laura D. Russell \\ Department of Communication \\ Denison University
}

[This is an Accepted Manuscript of an article published by Taylor \& Francis Group in Health Communication on January 17, 2012, available online:

http://dx.doi.org/10.1080/10410236.2011.636479]

Author note: Jennifer J. Bute (Ph.D., University of Illinois at Urbana-Champaign) is an assistant professor in Communication Studies at Indiana University-Purdue University Indianapolis. Laura D. Russell (Ph.D., Ohio University) is an assistant professor in Communication at Denison University. A previous version of this paper was presented at the annual meeting of the Central States Communication Association in April 2010. The authors would like to thank Laura Ellingson and two anonymous reviewers for their helpful comments on this manuscript. Address correspondence to Jennifer Bute at jjbute@iupui.edu. 


\begin{abstract}
Two recent incidents in the United States generated a wealth of public discourses about a particular reproductive health issue: adolescent childbearing. As the media, political pundits, and private citizens pondered the meaning of these events, they expressed viewpoints, explanations, and possible solutions in mass-mediated outlets. We examined the discourses communicated in such outlets to understand how public discussion of teenage pregnancy reveals ideological assumptions about reproductive health, ideal family forms, and the expected lifecourse.
\end{abstract}

Key words: teenage pregnancy, reproductive health, public discourse, women’s health 
Public Discourses about Teenage Pregnancy: Disruption, Restoration, and Ideology

Teenage pregnancy is not a new issue to the public sphere (Coontz, 1992), though the perception that teenage childbearing is a social problem with disastrous consequences is relatively recent (Geronimus, 2004). Beginning around 1970, public concern centered on economic issues, with discourses claiming that teenage mothers and their offspring created an economic drain on society (Tapia, 2005). As welfare systems developed in the United States, the issue took shape in the political arena, where it became situated as a financial burden on taxpaying citizens (Tapia, 2005). Public outcry also framed this perceived social problem as a threat to public health, linking teenage childbearing to poor health outcomes for infants, including low birth weight and infant mortality (Geronimus 2003, 2004). Once established as a societal problem, teen pregnancy became part of moral discussions that situated expectant teen mothers as deviant citizens. Bolstering images of non-white and poverty stricken teens, the media perpetuated racial and cultural stigmatization of teen pregnancy (Kelly, 1996). As Geronimus (2004) noted, “well-publicized conventional wisdom continues to hold teen childbearing to be, in all cases and in every aspect, an antisocial act, and an important public health issue” (p. 157).

Discourses shaping teen pregnancy as an economic, political, and public health issue have continued developing into a master narrative used by the public to make sense of this perceived social transgression (Luttrell, 2011). Yet, the prevailing linguistic resources that characterize this unfolding narrative are challenged by recent events. During 2007 and 2008, two incidents in the United States generated a wealth of public conversation about adolescent childbearing: the pregnancy of teenage Nickelodeon television star Jaime Lynn Spears and the pregnant teenage daughter of Republican vice-presidential candidate Sarah Palin. In contrast to images of impoverished teens, Spears and Palin became public icons for teen pregnancy. As 
media coverage of their pregnancies unfolded, commentators, pundits, and the public at large engaged in impassioned debates about the implications of these unexpected pregnancies of young idols.

We position media coverage surrounding these two events as an opportunity to examine the rhetorical shaping of teen pregnancy and uncover how pervading ideologies about reproduction, ideal family forms, temporality, and the expected lifecourse (Becker, 1997) are both reflected in and produced through discourse (Cheek, 2004; Lutpon, 1992, 2003). Recognizing that meanings are constructed “in the symbolic space between reader, text, and context” (Harter, Kirby, Edwards, \& McClanahan, 2005, p. 85), we offer our particular reading of these discourses and invite readers to enter into emerging conversations about women's sexual and reproductive health choices, more broadly, and adolescent pregnancy, more specifically. We begin by providing information on the prevalence of teen pregnancy in the United States and reviewing previous work on the social construction of teen pregnancy. We then present an overview of the two cases we examined to familiarize readers with the key characters and stakeholders involved. Next, we detail the theoretical and methodological sensibilities that guided our analysis and present our reading of the ideological assumptions implied in public dialogues about these events (Lupton, 1992).

\section{Prevalence of Teen Pregnancy in the United States}

Since the Jamie Lynn Spears and Bristol Palin cases made headlines in popular media, the issue of teen pregnancy has become seemingly prevalent. Yet, competing views and contradictory statistics suggest confusion regarding the widespread nature of this phenomenon. For instance, Malhotra (2008) reported in the Journal of American Physicians and Surgeons that 750,000 teen pregnancies occur each year, a finding she borrowed from the Guttmacher Institute. 
Malhotra then followed this statistic by stating, “This means that about one in ten teenage women get pregnant in a year-or about one in five sexually active teenage women” (2008, p. 89). While this particular statistic frames teen pregnancy as a rather pressing and growing concern, alternative reports suggest otherwise. For instance, TIME Magazine editor, Nancy Gibbs (2008), reported the same data from the Guttmacher Institute (regarding the recorded 750,000 pregnancies in a year), but noted that this current count is actually “down $36 \%$ from the peak in 1990” (p. 36). The statistical data appearing on both the Guttmacher and National Campaign to Prevent Teen Pregnancy websites also evidence decreasing trends in the pregnancy rates among teenagers since the 1990's. Thus, the vast differences in how teen pregnancy rates are reported make gauging the prevalence of this phenomenon highly ambiguous, even as seemingly ubiquitous media coverage makes teen pregnancy seem like a growing trend.

\section{Media Constructions of Teen Pregnancy}

Jamie Lynn Spears and Bristol Palin made headlines in popular media that amplified public discussions about teen pregnancy. Over the past few decades, scholars have been increasingly critical of the ways the media has portrayed adolescent pregnancy. In her study of Canadian newspaper and magazine articles published between 1980 and1992, Kelly (1996) consistently found pregnant teens stereotyped as welfare dependent or coming from troubled backgrounds. Despite evidence to challenge these depictions (Clark, Dechman, French, \& MacCallum, 1991; Geronimus, 1997; Geronimus \& Korenman, 1992), the media continue to promote stigmatizing images of adolescent pregnancy (Kelly, 1996,1997; Luttrell, 2011). Moreover, gendered biases transcend those of race and class, as females remain the resounding targets for blame. As media cast a shameful spotlight on young women, females are commonly portrayed as responsible for poor choices and “wrong” actions (Kelly, 1996). 
Some scholars have suggested that media constructions of unplanned pregnancies are shifting. For instance, Hoerl and Kelly (2010) analyzed three recent films that portray unintended pregnancies, including the pregnancy of the teenager in the movie. Juno, and concluded that these portrayals emphasize the role of women's agency in reproductive decision-making while simultaneously rejecting the notion of an unplanned pregnancy as a shameful act. However, the authors conclude that despite these unconventional portrayals, media "ultimately restore the myth of motherhood” (p. 374) by failing to paint a full and complex picture of the social constraints that make parenting a challenge for women with few social resources. With few exceptions, media discourses appearing in newspapers, magazines, feature films, and television programs have largely shaped public understandings of teen pregnancy as comparable to a crime that should be ridiculed and prevented. But how do the media respond when this "crime" is suspected among teen idols who do not fit the stereotyped depictions of pregnant teens? The cases of Jamie Lynn Spears and Bristol Palin undoubtedly challenge the iconic images of welfare-dependent mothers struggling to care for their unplanned children.

\section{Case Overviews}

“...fans gasped in shock Tuesday night as news broke that 16-year-old actress Jamie Lynn Spears, younger sister of Britney, had confirmed exclusively to OK! that she is expecting her first child”(OK! Magazine, 2007, December 16). Following Jamie Lynn Spears’s announcement of her pregnancy, her story took head-wave in news media. Reporters across the world broadcasted the shocking response to this teen-idol’s “fall.” Controversy spilled over the confusing messages sent to young audiences, particularly pre-teen girls, by the pregnancy of the Nickelodeon television star. Discourses, including those of Jamie Lynn herself, her mother, 
Lynne, Nickelodeon network executives, and a variety of news journalists shaped understandings of the event as the story of this teen idol's pregnancy unfolded in the public spotlight.

“The 44-year-old Alaska governor set the political world spinning faster than Hurricane Gustav on Sept. 1 when she announced that her teen daughter is pregnant and planning to marry her boyfriend, Levi Johnston” (OK! Magazine, 2008, September 2). Shortly after becoming Senator John McCain’s vice presidential running mate for the 2008 presidential election, Sarah Palin revealed that her seventeen-year-old daughter, Bristol, was pregnant. Palin’s news received widespread coverage that challenged the public to question traditional value systems for families. Discourses from politicians and concerned citizens depicted the treacherous intersection between values for national leadership and conservative family norms.

After the initial announcements of these unplanned pregnancies, public discourses debating the causes and consequences of adolescent pregnancy surged. We examine the discourses surrounding the Jamie Lynn Spears and Bristol Palin cases to analyze the discursive tensions and resolutions configuring these events. Our goal is to expose the ideological dimensions reflected in, reified and challenged by the rhetorical framing of teenage pregnancy in the context of teen role models.

\section{Theoretical Sensibilities and Research Analysis}

Our approach to this analysis is informed by our theoretical sensibilities to particular meanings of discourse and notions of temporality. Informed by social theory, we used Lupton’s (1992) definition of discourse as a guiding lens for our collection of public conversations and our subsequent analysis. Lupton defined discourse as “a group of ideas or patterned way of thinking which can both be identified in textual and verbal communications and located in wider social structures” (p. 145). Scholarly attention to “a group of ideas or patterned way of thinking” and 
the broader social context in which discourses are embedded is critical given that language is not natural, neutral, transparent, or value-free (Cheek, 2004). Through critical scrutiny of discourses, scholars can uncover how language reflects and perpetuates existing power structures and reveal the manner in which dominant ideologies are produced through rhetorical devices and linguistic arrangements (Lupton, 1992, 2003).

In particular, discursive analysis of health-related issues "has the potential to reveal valuable insights into the social and political contexts in which varied discourses about health take place” (Lupton, 1992, p. 146). In the case of teenage pregnancy, for example, advocating for sex education or designing health campaigns that promote safer sex practices for teens necessitates an understanding of the broader contexts in which debates about sexual health occur. As Dutta and Zoller (2008) noted, "meanings of health are continually constituted in everyday discursive practices, drawing our attention to the ways in which discourses constrain and enable possibilities for everyday practices” (p. 32).

Our decision to examine public discourses also reflects our sensibility to the temporal nature of socially constructed events. We refer to Carr (1986) and Ricoeur (1965) to explain the constitutive nature of lived experience, specifically in how meanings from the past, actions of the present, and provisions of the future interweave. Given the dynamic flux between moments in time, we recognize teen pregnancy as a phenomenon that is continually contested and changing in meaning over time. Thus, this particular issue embodies not only contrasting views within one instant, but also contrasting views across time. The temporal reality that constitutes experience allows us to consider the different cases in our analysis as intertextually woven (Lupton, 2003). In other words, these events are contextually rendered and, therefore, made sense of concurrently and not in isolation. 
Moreover, these events are entrenched in larger social and cultural contexts that dictate specific social norms regarding the timing of reproduction and preferences about how the expected lifecourse should unfold over time (Becker, 1997, Geronimus, 2003). In general, notions of such expectations in the United States revolve around an ideology of continuity. Becker claimed that the idea of continuity (i.e., the expectation of an ordered and predictable life) is so deeply embedded in Western culture that it amounts to an ideology. In the United States, dominant norms suggest an expected lifecourse that includes delayed sexuality and childbearing followed by the eventual formation of particular family types, typically married heterosexual couples with children (also see Bute \& Jensen, 2010; Geronimus, 2003). Unexpected events that shatter a sense of order are framed as disruptions that require restoration and sense-making. Cultural documents, such as various forms of discourse reveal discursive efforts to make order out of chaos and demonstrate the moral force of normalizing ideologies (Becker, 1997). For our analysis, we considered how conventional values and beliefs shape the knowledge claims presented in the various opinions that emerged in public discourses.

For our research analysis, we began by gathering discourses relevant to the announcement of Jamie Lynn Spears’ pregnancy and the public revelation of Bristol Palin’s pregnancy. Given that these events occurred within the span of one year, we narrowed our search to examine discourses from November 2007 to January 2009. We began searching the LexisNexis database by specifying the time frame and using the key terms, "teen pregnancy" "Jamie Lynn Spears,” and "Palin pregnancy.” This search resulted in a collection of news articles and transcripts from a variety of popular broadcasts and outlets, including those from ABC, CBS, NBC, TIME Magazine, National Public Radio, the New York Times, and the Boston Globe. As we combed through articles and transcripts, we noted that many of them repeated word-for-word 
content distributed by the Associated Press (AP), and we eliminated duplicate pieces. Following the collection of these discourses, we conducted a Google search using the aforementioned key terms. This search allowed us to explore a wider variety of online magazines and news sites targeted at teen audiences. We gathered seventy-two distinct articles, a third of which came from Lexis-Nexis and the remainder from broader public venues online. The culmination of our data collection encompasses (a) discourses shaping the depiction of specific teen pregnancy cases and (b) broader public views about teen pregnancy in response to the events.

Throughout data collection and analysis, we met regularly and developed a reflexive journal to log our ongoing thoughts, thus creating an audit trail (Cheek, 2004). We relied on the journal to track our progress with data collection and analysis and to note theoretical insights, points of contention, and ongoing questions. In addition, following our discussions about the discourses, we documented concepts and inquiries to guide our data collection procedures. Thus, the reflexive journal exemplified our engagement with iterative sense-making as we constructed meaningful reflections and insights for interpreting the public discourses about teenage pregnancy. In the following section we offer our reading of these discourses and then discuss the ideological dimensions revealed by our analysis. Throughout these sections, we cite only the sources of discourse we reference directly in this manuscript. A complete list of all the discourses we analyzed is available from the authors by request.

\section{Analysis}

\section{Teen Pregnancy as Disruption}

The discourses evolving from the two pregnancy events explicitly draw attention to their disruptive nature. In particular, a sense of "shock” was apparent in the wide coverage of the Spears case. As Molly MacDermot, editor of teen magazine Twist and M, observed when 
comparing Jamie Lynn to her sister Britney, "What's shocking is that she’s [Jamie Lynn] always been the clean, down-to-earth one” (Olson, 2007, p. C4). MacDermot explained that teen pregnancy disrupts the expected image of a teen role model, and thus is framed as detrimental to both micro and macro sectors of communal life.

The rising shock that often accompanies the announcement of pregnant teens is further emphasized by the media’s use of disruptive metaphors to illustrate such events. As broadcasted on ABC News, “The news that 16-year-old Jamie Lynn Spears is pregnant caused an earthquake in the 'tween' world. Now it's time for the aftershocks, especially for moms” (2007). Comparing Spears's pregnancy announcement to the onset of an earthquake contextualizes the magnitude of disruption ascribed to this event. Such amplification is emphasized by the language and metaphorical images depicted by public discourses, thus evidencing how discourses socially construct the negative image of teen pregnancy.

Even so, the discourses we examined allowed us to see how public understandings of teen pregnancy are also contextually rendered and shaped differently over time. The immense disruption portrayed for the Spears case was often downplayed in the public responses to the Palins’ situation. For instance, as reported in The Boston Globe:

The news that vice presidential candidate Sarah Palin’s 17-year-old unmarried daughter is five months pregnant has heightened media concern regarding teen pregnancies. Given that we are the industrialized nation with the highest adolescent birth rate in the world, however, this is not a new problem. (2008, p. A10) While disruption is implied by the "heightened media concern," the statement minimizes the magnitude of disruption by noting that adolescent birth rates are "not a new problem.” Some commentators even went as far as to posit the Palin pregnancy as any everyday matter. As Sylvia 
Figuero, a teen mother from Los Angeles, stated during her interview with National Public Radio, "Seventeen is not a big deal. A lot of girls are pregnant at that age. Well. Most of the girls do it. I don't know why they make it a big thing. And that doesn’t have to do anything with politics and such” (Norris, 2008). Figuero attempted to normalize the instance of teen pregnancy while also making the claim that family issues and politics should be treated as two separate worlds. Hence, in this case, teen pregnancy is regarded as a peripheral rather than pervasive event of everyday life. Such is not the case for the Spears pregnancy, where discourses targeted teen pregnancies as the core of shocking and intolerable crises.

\section{Teen Pregnancy as Consequential}

The extent of disruption attributed to each of the pregnancy events we observed set the tone for ensuing debates over consequential concerns. In particular, public discourses constructed an image of layered chaos through narrating the traumatic effects teen pregnancy has on the personal lives of teens and their families as well as on society at large. On a personal level, both Jamie Lynn Spears and Bristol Palin described their feelings about becoming pregnant. For instance, Jamie Lynn commented, “As soon as I found out for sure from the doctor, I took two weeks to myself where I didn’t tell anybody” (OK! Magazine, 2007, December 20). Jamie Lynn explained the difficulty she had coping with the realization of her pregnancy and how her initial shock and shame made it difficult to open up to others. Upon receiving the news of her daughter’s pregnancy, Lynne Spears explained to NBC News, “I was in shock. I just kept saying, you're-I think I was just in shock. And then I started to cry. And then she started consoling me, you know, at that point” (Viera, 2008). But after her initial shock, Lynne was reportedly very supportive of her daughter’s situation. 
Bristol Palin responded to her pregnancy situation similarly to Jamie Lynn, as she shared with Fox News the experience of telling her parents:

Well, we were all sitting on the couch, my best friend and Levi, and we had my parents come and sit on the couch, too. And we had my sisters go upstairs. And we just sat them down, and I just-I couldn’t even say it. I was just sick to my stomach. And so finally, my friend just, like, blurted it out. And it was just, like-I don’t even remember it because it was just, like, something I don’t want to remember. (Van Susteren, 2009) Bristol described her desire to avoid revealing her pregnancy, news that she anticipated would devastate her family. Yet, the Palins reacted differently, or at least presented themselves differently, to the public than Bristol may have expected. Similar to Lynne Spear's initial struggle with and subsequent support for her daughter's situation, Sarah Palin’s testimony exemplified her hope and strength. As reported by the Associated Press:

Our beautiful daughter Bristol came to us with news that as parents we knew would make her grow up faster than we had ever planned. As Bristol faces the responsibilities of adulthood, she knows she has our unconditional love and support. (Murray, 2008) Sarah Palin’s response demonstrated her attempt to ameliorate perceivable consequences by referring to the stabilizing values of unconditional love. Therefore, both the Spears and Palin cases exhibit how the initial disclosure of teen pregnancy is perceived as having disruptive force. However, the communicative events following such disclosure play a major role in either ameliorating or amplifying the disruptive course of teen pregnancy disclosures.

When taking into account the personal dimensions of these cases, we must consider the broader discourses within which these different events take shape. Inevitably, each reported case of teen pregnancy becomes associated with and chronicled in the evolving history of this 
controversial health issue. The flux between historically grounded values for an idealized lifecourse and the contingent circumstances of present time disrupts the normalizing conditions that premise society's prosperous future. Not only were these events portrayed as disruptive, but also as consequential to U.S. society. With regard to the Spears case, Fox News reported, "The big issue and it seems to have everybody talking is about a teen idol's pregnancy and how it's going to impact her young and impressionable fans” (Nauert, Gibson, \& Fuller, 2007). Comments like this suggested that this isolated case has larger consequences to society’s impressionable conceptions of teen pregnancy. These discourses, therefore, framed this event and similar others as disruptive circumstances leading to greater social concerns. Even with regard to the Palin case, commentators noted the potential harm Bristol's pregnancy could have on the Republican campaign. As reported on CBS Evening News,

I don't think this is going to be a big deal down the stretch” of the election, said a top House Republican aide, speaking on the condition of anonymity. "But it does create a level of uncertainty about Palin, among Republicans and the media, and that can be a huge negative for Palin’s candidacy. (Bresnahan, 2008)

While the House Republican aide downplayed the impact that Bristol's pregnancy would have in the long run, CBS News framed Bristol Palin’s pregnancy as having a “huge negative” influence on her mother's campaign. This difference in perspectives illuminates the ambiguity that pervades the disruptive theme carried throughout teen pregnancy discourses. Overall, the portrayal of these events through public discourses rhetorically constructs evolving crises of repeated disruptions and threatening consequences. Restoring Order When Teen Pregnancy Occurs 
Just as the public discourses surrounding these cases revealed underlying assumptions about the disruptive nature of adolescent pregnancy, discursive features of these same texts also indicated how the characters tied to these cases, the dominant media, and the public at large sought to makes sense of these disruptions. By seeking explanations, idealizing family life, emphasizing personal responsibility, and framing events as teachable moments, public discourses included temporal shifts toward restoration and sense-making.

Seeking explanations. One step toward restoring order to a chaotic situation (Becker, 1997) involves searching for explanations to understand why the event occurred in the first place and assigning blame to responsible parties. Reflecting on the confusion that Jamie Lynn's young fans felt after the news of her pregnancy, Denise Restarui, founder of a social networking site for young girls, lamented, "You can see that they're really trying to find an answer and some hope to how could their idol, someone who was the purer sister of the Spears sisters, how could this have happened?” (Norris \& Block, 2007). As pundits made sense of these cases, they answered this query by blaming poor parenting (read: poor mothering), Hollywood's glamorization of teen pregnancy, abstinence-only education, and a host of other complex factors.

In particular, Jamie Lynn's mother, Lynne Spears, was vilified in many accounts. As one commentator noted on Fox News, “I think that she’s [Jamie Lynn’s mother] got to take a lot of the blame. Clearly, she's not had the communication lines open between herself and Jamie Lynn” (Nauert, Gibson, \& Fuller, 2008). Some pondered whether Lynne was a worse mother than her oldest daughter Britney, the pop superstar notorious for driving with a toddler in her lap and her recent stint in rehab (Hammer \& Anderson, 2008). After Jamie Lynn gave birth, Lynne appeared on the Today Show and, indeed, took responsibility: "As a mother, don't—I mean, don’t we always blame ourselves...I took all the blame” (Vieria, 2008). 
The media and abstinence-only sexual health education were also scapegoats in public discourses surrounding these cases. The Jamie Lynn Spears pregnancy was mentioned in discussions of the Palin case (Hammer, Anderson, \& Moos, 2008). Hollywood’s glamorization of teen pregnancy in recent movies like Juno, which features a precocious teenager who after becoming pregnant quips about what other shenanigans she can get into, came under fire as commentators sought to understand the fall of idols like Jamie Lynn. Sarah Palin's support of abstinence-only sex education also became a source of controversy when her daughter's pregnancy was made public (Bash, 2008; Hammer, Anderson, \& Moos, 2008). Across both cases we observed, attempts to pinpoint a primary cause for the disruption are ubiquitous in public discourses and represent one means of addressing the disorder caused by teenage pregnancy.

Normalizing and idealizing the family. The idealized norms of family life implied by the public discourses surrounding these cases illustrate another means of seeking restoration. In particular, discourses detailing the cases of Jamie Lynn Spears and Bristol Palin invoked images of the "typical” family in the U.S. as a means of restoring order and framed adolescent pregnancy as something that happens to everyday people, thus attempting to integrate these potentially problematic events with the ebb and flow of everyday life.

Discourses about Jaime Lynn consistently portrayed a loving and supportive family who eventually rallied around her after her shocking announcement. For instance, the original OK! Magazine article that announced Jamie Lynn's pregnancy to the world on December 17, 2007, described Lynne as "very supportive” after her initial shock, and the teen herself claimed that the circumstances of her pregnancy strengthened her relationship with her mother. When the baby was born, birth announcements in the press emphasized the presence of her family: "Both mom and baby are healthy and happy... They are surrounded by their close relatives, including Jamie 
Lynn’s older sister Britney, mother Lynne, father Jamie, and brother Bryan” (The Insider, 2008). Similar adulations of family support and resilience are present in the media coverage of the Bristol Palin case. In an extensive interview with Greta Van Susteren of Fox News, Bristol herself expressed her gratitude for her family’s devotion and assistance with caring for her newborn: "But my mom and my whole family-I am just so blessed to have them because they help out a lot, more than I would have ever imagined I guess” (2009).

Discourses about both Spears and Palin exalted plans for eventual marriage and the joys of motherhood. Bristol and Levi Johnston continually highlighted their plans for marriage: almost all stories announcing the birth of the baby in December 2008 included the couple's intention to wed in the near future. As Johnston himself stated, "We both love each other. We both want to marry each other. And that's what we are going to do. We were planning on getting married a long time ago with or without the kid” (US Magazine, 2008). In interviews after the birth of her daughter, Jamie Lynn "painted an ideal picture of new parenthood” in which she and Casey, whom she planned to marry, kept the baby’s bassinet near their bed and took turns caring for their infant (Kaufman, 2008). The 16-year-old said, "being a mom is the best feeling in the world” (Kliff, 2008).

In the midst of discursive efforts to idealize particular family forms through an emphasis on plans for marriage and the glorification of motherhood, characters in the Palin case, including members of the Republican party, also sought to normalize teen pregnancy as something that happens to real people (Van Susteren, 2009; Marcus, 2008), suggesting that "teen pregnancy is a fact of life”(OK! Magazine, 2008, September 2). Governor Palin explained to Van Susteren of Fox News: 
I think Bristol's kind of an example of, truly, it can happen to anybody. Bristol, great athlete, great student, great aspirations that she had for herself, plans that didn't include a baby, of course, but it did happen to her and now again, less than ideal circumstances, but we make the most of it. (2009)

Palin’s “it can happen to anybody” mentality was widely reflected in public discourses. In particular, early commentaries reflecting on Bristol's pregnancy, and many Republican strategists theorized that coping with a teenager's pregnancy is a challenge with which many Americans can identify (Bresnahan, 2008). As one young woman interviewed for a National Public Radio report put it, "I think that might give her a little more perspective, a little more sympathy for the average American because a lot of the times I think we see politicians as these people on pedestals. We don't see them as real people. But this is as real as it gets.” (Norris, 2008).

Emphasizing responsibility. In addition to seeking explanations and attempting to construct an idealized family, public discourses surrounding these events also attempted to underscore the importance of pregnant adolescents taking responsibility for their actions and urging others not to follow in their footsteps. Nickelodeon's public statement following the announcement of Spears' pregnancy lauded her “decision to take responsibility in this sensitive and personal situation” (www.brittneyspy.com, 2007). Jamie Lynn herself expressed, “I’m trying to do the right thing" (www.brittneyfans.org, 2007); "I have to act like an adult and take responsibility for what I did” (OK! Magazine, 2007, December 16). Even so, she made it clear in the original $O K$ ! article that young girls should not emulate her actions: "I definitely don't think it's something you should do. It's better to wait” (OK! Magazine, 2007, December 16). Likewise, Bristol Palin's family celebrated her choice to keep and raise her baby, and repeatedly 
emphasized that the decision to do so was Bristol's choice, not the choice of her family (Bash, 2008). Yet Bristol, like Jamie Lynn, made it clear that young girls should not follow the same path she did because teenage motherhood is far from glamorous (Van Susteren, 2009). Thus, public discourses encouraged young mothers to take responsibility for their choices by raising their children while simultaneously reminding consumers of discourses that teen pregnancy is still a disruption, a less than ideal circumstance that young girls should try to avoid.

Framing the event as a teachable moment. At the same time that public discourses emphasized the significance of teenage moms taking ownership of their choices, public conversations about these events also attempted to restore order by framing them as teachable moments. In particular, events were framed as an opportunity for parents to talk to their children, especially their daughters, about adolescent sex and pregnancy and to reconsider the role of sexual health education in schools. Public figures sought to restore order by using the events to prevent future pregnancies. The Today Show, for instance, featured a segment in which a guest expert taught parents how to talk to their kids about the thorny issues surrounding teen pregnancy, stating, “you have to see this as an opportunity” to talk to kids about sex, morals, and values (Gregory \& Larson, 2007). And speaking about the Jamie Lynn case, Bill Albert, deputy director of the National Campaign to Prevent Teen and Unplanned Pregnancy stated, "This is a teachable moment. Parents tell us time and time again that they want to address [this], but they don’t know where to start. Jamie Lynn Spears is the perfect place to start” (Hesse, 2007). Other commentators lamented that such efforts might be futile. In a Washington Post editorial, one columnist reflected that:

Bristol Palin's pregnancy may be the ultimate teachable moment....Being a teenager means taking stupid risks. The best, most attentive parenting and the best, most 
comprehensive sex education won’t stop teenagers from doing dumb things. The most we as parents can hope for is to insulate our children, as best we can, from consequences of their own stupidity. (Marcus, 2008)

Despite these assumptions about teenage “stupidity,” Bristol Palin herself has become an activist for teen pregnancy prevention, even appearing on various morning shows to promote awareness on National Teen Pregnancy Prevention Day. Thus, the quest to frame her own experience as a teachable moment lives on for Bristol.

\section{Discussion and Conclusions}

In light of calls from scholars to employ discourse analysis as a method for understanding how communication about particular health issues produces, reproduces, and reifies dominant ideologies (Lupton, 1992, 2003), we devote the final section of this paper to a deeper critique of these public conversations. Through critical analysis of discourses surrounding the pregnancies of Jamie Lynn Spears and Bristol Palin, we identified themes relevant to debates across time concerning teen pregnancy. Because of the idol status of Spears and Palin, considerable sensemaking efforts followed the initial disruptive character of these events. Restorative efforts have since generated a wealth of discourses encouraging public discussions not only about preventing pregnancy, but also about how teens who do become pregnant should pursue their future lives. That is, just as these cases have become icons for preventative programs, they have also drawn attention to restorative approaches for teens raising children. In this closing discussion, we reflect on themes that parallel and contrast with previous findings concerning the discursive construction of teen pregnancy. We then acknowledge the current state of public discourses manifest in media programs about this issue, and infer how such discourses were furnished through the cases observed in our analysis. 


\section{Dominant Ideologies in Discussions of Teen Pregnancy}

The rhetorical framing of adolescent pregnancy as a disruptive event reveals underlying assumptions about social class, dominant values about ideal family forms, beliefs about the expected life course, and responsibility for making decisions concerning sexuality and reproductive health. We discuss these issues while offering deeper reflections for readers' inquiry.

Unquestioned Assumptions. Though the unplanned pregnancies of Jamie Lynn Spears and Bristol Palin were discursively framed as highly unexpected and disruptive events, public conversations about their situations did not include explicit reflection on the economic burden and potential health risks posed by their pregnancies. In this way, discourses about Spears and Palin differ markedly from the concerns typically voiced in public debates about adolescent childbearing. Structural barriers that make young motherhood difficult, such as the lack of access to health care, unstable employment, and interrupted educational opportunities, went largely unexamined in discussions of Spears and Palin. Because both women came from well-known and well-to-do families, the public took for granted that Bristol and Jamie Lynn had the financial resources to care for themselves and their children, making it easier to celebrate each starlet's “ability to make the right choice and exercise proper moral reasoning” (Hoerl \& Kelly, 2010, p. 361). Yet, in leaving such issues unquestioned, public discourses about these two cases missed an opportunity to address the numerous variables that shape women's reproductive choices, including income, educational background, relational stability, and subgroup norms that might actually promote early childbearing (Bute \& Jensen, 2010; Jensen \& Bute, 2010; Hoerl \& Kelly, 2010). 
Ideal Family Forms. By framing a reproductive health issue like teenage pregnancy in terms of family efforts to promote responsibility and bond as a cohesive family unit, public conversations about these events advanced a narrow definition of the ideal family in the United States. More specifically, the concept of a heterosexual mother and father who raise their biological child(ren) as a married couple was consistently promoted as editorials and official press releases applauded the efforts of teenage mothers to keep their babies and develop relationships with the fathers of their children by committing to eventual marriage (though, as recent events have unfolded, these marriages have not come to fruition; see Weiner, 2009). Spears and Palin, for instance, were lauded by their families and the public at large for taking responsibility after they discovered they were pregnant. Though never explicitly stated, this celebration of "responsibility" implies that giving birth, getting married, and raising a child is the preferred decision. Moreover, those who make this decision act in coherence—or adherence- to a master narrative sustaining normative values and beliefs for American families. Public efforts made to preserve family norms, therefore, legitimize teen pregnancy as becoming a more acceptable rather than disruptive life experience. This shift invites more public discussion about teen pregnancy, making it a less taboo issue. At the same time, however, such discussions may simply emplot teen pregnancy into normative stories that significantly limit the acceptable options available for adolescent parents.

Though "shocked" and "scared," both young mothers emphasized their personal choice to have and raise a child at a young age. One wonders whether and how Jamie Lynn and Bristol would have been celebrated if they had publicly committed to giving their children up for adoption or opting for abortion, both of which can be potentially responsible choices. The absence of discourses addressing alternative options and the consistent celebration of the choice 
to give birth and get married reinforces dominant ideals and markets moral standards assumed possible for all expecting teen mothers. Less obvious to the public eye are the resources available for celebrities that are not afforded to all pregnant teens (Luttrell, 2011). Therefore, the moral messages condoned, at least by the Spears and Palin cases, may impose implausible expectations for many pregnant teens.

Control over the Expected Lifecourse. The particular events, roles, and popular beliefs about teen pregnancy are punctuated through the ways discourses create and organize time. A dominant ideology prevails in the narrative constructions of the cases that determines the expected trajectory of events from adolescence to adulthood. Public values for first finishing school, then getting married, and last, having children, become clearly apparent when teens who are still in school and not married become pregnant. Therefore, teen pregnancy creates a disruption to the social ordering of time, which then threatens public understandings of what should constitute the good life. Consequently, pregnant adolescents are often subjugated as immoral in character when their lifestyles become compared to the cohering values holding together narratives of the American Dream—-the good life.

The initial reactions in public discourses surrounding the events we observed projected scandalous depictions and shocking sensations to amplify culturally sustained antagonistic beliefs about teen pregnancy. However, over time popular press releases provided storied accounts of how teens proceeded with their lives, thus helping the public understand that there is life after pregnancy. The emphases on love and support and marketing of smiling images of teen moms with their babies complicate traditional conceptions of the good life by suggesting that pregnant teens can still pursue happy, morally-sound lives. This is not to suggest that teen pregnancy has become an applauded lifestyle, as cases involving Spears and Palin are still 
commonly referenced as teachable moments for what not to do. However, these new images of teen pregnancy instigated public conversations not simply about preventing adolescent pregnancy, but reacting to circumstances when teens are expecting children. This finding parallels the themes of various reality-based television programs showing how teens manage their lives once their children have been born. We will address these programs in brief momentarily. To conclude the current discussion, we bring attention to the heteronormative values implicated in the narratives surrounding these events, particularly with regard to the gendered responsibilities assumed for reproductive health and pregnancy issues.

Women as Responsible for Reproduction and Parenting. The discursive framing of pregnancy in this collection of discourses also serves to reify women’s roles in taking responsibility for reproductive health and related decision-making, including parenting. This finding aligns with previous claims revealed in studies on prevention campaigns (Tapia, 2005), health pedagogies (Luttrell, 2011) and media productions (Hust, Brown \& L’Engle, 2008) related to teen pregnancy. In the current study, many public reports referred to men, yet men were either framed as potential or alleged fathers of unborn children or were highlighted as soonto-be husbands in discussions of the possibility of eventual marriage. They were rarely featured as part of the decision-making process as the press celebrated young women's decisions to take responsibility by having and raising a baby. Thus, men (fathers) were tangential to the central issue of teenage childbearing and eventual parenting while young women (mothers) remained the focus of media attention and public speculation.

While we must recognize that the young women were featured as central characters due to their celebrity status (in the case of Spears) and their association with a public figure (in the case of Palin), we would venture to guess that if a prominent politician's son were to impregnate 
a teenage girl, he would be unlikely to make the media talk show circuit on National Teen Pregnancy Prevention Day announcing his involvement in health education efforts. Moreover, we found that the parenting ability of mothers of pregnant daughters was scrutinized heavily. For instance, Lynne Spears herself admitted that her daughter's situation was a direct result of her own failures as a parent. Yet, the parenting practices of fathers, including Jaime Lynn Spears’ father, remained largely unquestioned. Thus, public discourses reinforce the notion that women are responsible for reproduction, childbearing, and parenting, putting the onus of responsibility on women and neglecting the experiences of men. We join other scholars of health communication who have questioned and problematized the stubborn and consistent tendency to frame reproductive health and parenting as women's issues in public discourses and sexual health education (Bute, Harter, Kirby, \& Thompson, 2010; Thompson, 2010).

\section{The Tenuous Nature of Restoration}

Through critical examination of the language used to represent efforts toward restoration after the disruption of teenage pregnancy, we see that achieving coherence in the face of “stunning” events is a fragile enterprise, characterized by dialectical tensions that highlight the constant interplay between the distress of disruption and the desire for restoration. Moves to restore order in the face of life-changing circumstances are necessarily incomplete and perhaps unfinalizable. Moreover, restoration concerning the issues uncovered in this study is twofold. On one hand, over time the media coverage constituting the public stories of Spears and Palin seeks restoration for each of these particular circumstances (as earnest attempts were made to pinpoint fault, depict families coming together, and show the "good life" after children were born). On the other hand, these incidents issued a need for restoration of society at large for coping with the reality that despite preventative efforts, teens can and will still become pregnant. In addition to 
attending to preventative precautions, the media responded to these cases with images and stories for helping the pubic conceive that there is life-possibly good life-for adolescent parents.

Media productions depicting the lives of pregnant teenagers gained popularity during and shortly after the events of Spears and Palin. For instance, in the summer of 2008, ABC Family released The Secret Life of the American Teenager, a drama series capturing the day-to-day experiences of teens dealing with unexpected pregnancy. Subsequently, in 2009 MTV premiered two reality-based programs, Teen Mom and 16 and Pregnant, both of which remain high-rated shows for the network today (see mtv.com). While we refrain from discussing these examples in detail, we use them to illustrate how the incidents observed in our analysis further instigated or at the very least contributed to public interests in learning about the lives of pregnant teens. That is, the preventative, and at times, shaming discourses that once predominated the mediated landscape of teen pregnancy have recently been sided by productions that focus on how adolescents experience parenthood after their children are born.

Disruption and restoration constitute dialectical tensions through which sense-making of coherence takes shape. The ways we story our lives lead us to conceive of disruption only when our normative assumptions are violated. Hence, even the most modest forms of disruptive experience appear against the background of conceived normality. Our vision of disruption is therefore inseparable from our restorative viewpoints. When we realize disruption in the lifecourse, we do so by simultaneously trying to configure this perceivable difference coherently with our normally conceived experiences. Disruption transpires a reconfiguration of coherency that is aided through restorative attempts to make sense of new meaning with past understandings. The co-constitutive nature of both disruption and restoration, therefore, sustains a tension that motivates continual sense-making for personal experiences that surpass 
generalizable expectations for life. We examined this tension as continually manifest in the discourses as the public wavered back and forth between justifying teen pregnancy and antagonizing its occurrence. Thus, by analyzing public discourses about this particular health issue, we revealed not only dominant ideologies about family forms and reproductive health, but also how the public reacts when events disrupt valued expectations.

\section{Practical Implications}

The pregnancies of Jamie Lynn Spears and Bristol Palin have already informed specific projects that seek to address teen pregnancy. For instance, the National Campaign to Prevent Teen and Unplanned Pregnancy dedicated entire sections of its web site to discussions of Spears and Palin and issued official statements when each young woman gave birth. The Candies Foundation, whose stated mission is to "to shape the way youth in America think about teen pregnancy and parenthood” recently featured Bristol and her young son in print ads with text reading, “I never thought I would be a statistic. More than 750,000 teenage girls will become pregnant this year" (see the candiesfoundation.org). Thus, various organizations have already seized upon these "teachable moments." Based on our analysis, we would add that as health educators and scholars of health communication ponder interventions for adolescents that are focused on sexual and reproductive health, it is crucial for them to understand the broader social and cultural context in which such interventions are embedded. In the cases of Spears and Palin, discussing with adolescents both what is present in discussion of these cases (e.g., celebration of particular choices) and conspicuously absent (e.g., men's voices, social constraints that make young motherhood challenging) would provide health educators an opportunity to engage in robust discussions of this complex health issue. 


\section{References}

ABC News. (2007). Former teen star applauds Jamie Lynn Spears for keeping baby. ABC News [Online archive]. Retrieved May 6, 2009, from http://abcnews.go.com/print?id=4032940.

Bash, D. (2008, September 2). Palin's teen daughter is pregnant. CNN.com. Retrieved March 1, 2009, from http://www.cnn.com/2008/POLITICS/09/01/palin.daughter/index.html.

Becker, G. (1997). Disrupted lives: How people create meaning in a chaotic world. Berkeley, CA: University of California Press.

Bresnahan, J. (2008, September 1). GOP establishment wrestles with Bristol Palin pregnancy. The Politico [Online article]. Retrieved March 1, 2009, from http://www.cbsnews.com/stories/2008/09/01/politics/politico/thecrypt/main4405099.shtl.

Bute, J. J., Harter, L. M., Kirby, E. L., \& Thompson, M. (2010). Politicizing personal choices? The storying of age-related infertility in public discourses. In S. Hayden \& D. L. O. B. Hallstein (Eds.), Contemplating maternity in an era of choice: Explorations into discourses of reproduction (pp. 49-69). Lanham, MD: Lexington Books.

Bute, J. J. \& Jensen, R. E. (2010). Low-income women describe fertility-related expectations: Descriptive norms, injunctive norms, and behavior. Health Communication, 25, 681-691. Coontz, S. (1992). The way we never were: American families and the nostalgia trap. New York: Basic Books.

Carr, D. (1986). Time, narrative and history. Bloomington, IN: Indiana University Press.

Cheek, J. (2004). At the margins? Discourse analysis and qualitative research. Qualitative Health Research, 14, 1140-1150.

Clark, S., Dechman, M., French, F. \& MacCallum, B. (1991). Mothers and children, on decade later. Halifax, NS: Nova Scotia Department of Community Services. 
Dutta, M. J., \& Zoller, H. M. (2008). Popular discourse and constructions of health and healing. In H. M. Zoller \& M. J. Dutta (Eds.), Emerging perspectives in health communication: Meaning, culture, and power (pp. 30-38). New York: Routledge.

Geronimus, A. T. (1997). Teenage childbearing and personal responsibility: An alternative view. Political Science Quarterly, 112, 405-430.

Geronimus, A. T. (2003). Damned if you do: culture, identity, privilege, and teenage childbearing in the United States. Social Science \& Medicine, 57, 881-893.

Geronimus, A. T. (2004). Teenage childbearing as cultural prism. British Medical Bulletin, 69, 155-166.

Geronimus, A. T. \& Korenman, S. (1992). The socioeconomic consequences of teen childbearing reconsidered. Quarterly Journal of Economics, 107, 1187-1214.

Gibbs, N. (2008, January 21). Why have abortion rates fallen? TIME Magazine [Online archive]. Retrieved September 29, 2008, from http://www.time.com/time/nation/article/0,8599,1705604,00.html.

Gregory, D. \& Larson, J. (2007, December 17). Pregnancy of Jamie Lynn Spears sparks concern about influence it may have on youth; Dr. Gail Saltz discusses how parents can address such issues. Today: NBC News [Televised program]. Retrieved October 10, 2008, from Lexis-Nexis.

Hammer, A. J. \& Anderson, B. (2008, September 17). One-on-one interview with Lynne Spears; Fabulous over 40; Katie Couric meets Sarah Palin; Lindsay Lohan caught in the middle of the Obama-McCain war of words; Alee Baldwin’s suicidal confession. CNN News [Televised program]. Retrieved September 2008, from Lexis-Nexis.

Hammer, A. J., Anderson, B., \& Moos, J. (2008, September 2). Bristol Palin’s pregnancy 
compared to Jamie Lynn Spears’; David Duchovny’s sex addiction; Reporters versus hurricane; Linda Hogan opening up about her relationship with Charlie Hill. CNN News [Televised program]. Retrieved September 29, 2008, from Lexis-Nexis.

Harter, L. M., Kirby, E. L., Edmonds, A. \& McClanahan, A. (2005). Time, technology, and meritocracy: The disciplining of women's bodies in narrative constructions of age-related infertility. In L. M. Harter, P. M. Japp, \& C. S. Beck (Eds.), Narratives, health and healing: Communication theory, research and practice (pp. 1-7). Mahwah, NJ: Lawrence Associates.

Hesse, M. (2007, December 20). The other spears does the bump; Britney's little sister no longer the, uh, role model. The Washington Post, p. C01.

Hoerl, K., \& Kelly, C. R. (2010). The post-nuclear family and the depoliticization of unplanned pregnancy in Knocked Up, Juno, and Waitress. Communication and Critical/Cultural Studies, 7, 360-380.

Hust, S, T., Brown, J. D. \& L’Engle, K. L. (2008). Boys will be boys and girls better be prepared: An analysis of the rare sexual health messages in young adolescents' media. Mass Communication \& Society, 11, 2-23.

Jensen, R. E. \& Bute, J. J. (2010). Fertility-related perceptions and behaviors among low-income women: Injunctive norms, sanctions, and the assumption of choice. Qualitative Health Research, 20, 1573-1584.

Kaufman, G. (2008, July 9). Jamie Lynn Spears describes ‘perfect delivery and new motherhood. Retrieved on September 20, 2008 from http://mtv.com/story/0,2933,369104,00.html. Kelly, D. M. (1996). Stigma stories: Four discourses about teen mothers, welfare, and poverty. Youth \& Society, 27, 421-449. 
Kelly, D. M. (1997). Warning labels: Stigma and the popularization of teen mothers' stories. Curriculum Inquiry, 27, 165-186.

Kliff, S. (2008, July 12). OK! magazine’s executive editor discusses their cover story on 17-yearold actress and new mom, Jamie Lynn Spears. Does the spread glamorize teen pregnancy? Newsweek Online. Retrieved September 20, 2008, from http://newsweek.com/id/145837.

Let’s talk about teen pregnancy. (2008, September 4). The Boston Globe, p. A10. Retrieved September 29, 2008, from Lexis-Nexis.

Lupton, D. (1992). Discourse analysis: A new methodology for understanding the ideologies of health and illness. Australian Journal of Public Health, 16, 145-150.

Lupton, D. (1994, 2003). Medicine as culture: Illness, disease, and the body in western society. Thousand Oaks, CA: Sage Publications.

Luttrell, W. (2011). Where inequity lives in the body: Teenage pregnancy, public pedagogies and individual lives. Sport, Education \& Society, 16, 295-308.

Malhotra, S. (2008). Impact of the sexual revolution: Consequence of risky sexual behaviors. Journal of American Physicians and Surgeons, 13, 88-90.

Marcus, R. (2008, September 2). The lesson of Bristol Palin. The Washington Post, p. A15. Retrieved September 29, 2008, from Lexis-Nexis.

Murray, M. (2008, September 1). The lesson of Bristol Palin. MSNBC.com. Retrieved March 1, 2009, from http://firstread.msnbc.msn.com/archive/2008/09/01/1318541.aspx

Nauert, H., Gibson, J., \& Fuller, B. (2007, December 21). Big Issue. Fox News Network [Televised program]. Retrieved September 29, 2008, from Lexis-Nexis. 
Norris, M. (2008, September 4). Teens respond to Palin, daughter's pregnancy. National Public Radio [Radio broadcast]. Retrieved September 29, 2008, from Lexis-Nexis.

Norris, M. \& Block, M. (2007, December 21). Girls and moms respond to teen star's pregnancy. National Public Radio [Radio broadcast]. Retrieved September 29, 2008, from LexisNexis.

OK! Magazine. (2007, December 16). World exclusive: Jamie Lynn Spears—“I’m pregnant”. OK! Magazine Online. Retrieved on March 2, 2009, from http://www.okmagazine.com/news/view/3425.

OK! Magazine. (2007, December 20). Lindsay: Jamie Lynn’s pregnancy is no big deal. OK! Magazine Online. Retrieved on March 2, 2009, http://www.okmagazine.com/news/view/3435.

OK! Reports. (2008, June 19). Jamie Lynn Spears has a baby girl. The Insider. Retrieved on September 20, 2008, from http://www.theinsider.com/news/982641_Jamie_Lynn_Spears_Has_Baby_Girl_OK_Rep orts.

OK! Staff. (2008, September 2). Cover Story: Sarah Palin’s baby scandal. OK! Magazine Online. Retrieved March 1, 2009, from http://www.okmagazine.com/news/view/8801.

Olson, E. (2007, December 24). What to do with taboo news when teenagers are your readers. The New York Times, p. C4.

Ricoeur, P. (1965). History and truth. (C.A. Kelbley, Trans.). Evanston, IL: Northwestern University Press.

Tapia, R. C. (2005). Impregnating images. Feminist Media Studies, 5, 7-22. 
Thompson, M. (2010). Who's guarding what? A poststructural feminist analysis of gardasil discourses. Health Communication, 25, 119-130.

US Magazine Staff. (2008, December 29). Bristol Palin gives birth to baby boy!

Usmagazine.com. Retrieved March 1, 2009, from

http://www.usmagazine.com/news/bristol-palin-gives-birth-to-baby

Van Susteren, G. (2009, February 18). Exclusive: A visit with the Palins. Fox News Network [Televised program]. Retrieved February 20, 2009, from http://www.foxnews.com/story/0,2933,494205,00.html.

Vieria, M. (2008, September 17). Lynne Spears, “Through the storm,” tells about daughter Jamie Lynn telling her she was pregnant. NBC News [Televised interview]. Retrieved October 10, 2008, from Lexis-Nexis.

Weiner, R. (2009, March 11). Bristol Palin, Levi Johnston split up: Confirmed. The Huffington Post. Retrieved September 28, 2009 from http://www.huffingtonpost.com/2009/03/11/bristol-levi-split-up-rep_n_173917.html 